\title{
A Phylogenetic Study of Korean Rodents (Muridae, Sciuridae) Based on Mitochondrial and Nuclear DNA
}

\author{
Gila Jung ${ }^{1, \dagger}$, Seo-Jin Lee ${ }^{2, \dagger}$, Chuel-kyu Kim ${ }^{3}$ \\ Hang Lee ${ }^{2, *}$ and Chang-Bae $\mathrm{Kim}^{1, *}$ \\ 'Department of Green Life Science, Sangmyung University, Seoul 110-743, Korea \\ ${ }^{2}$ Conservation Genome Resource Bank for Korean Wildlife and Research \\ Institute for Veterinary Science, College of Veterinary Medicine, \\ Seoul National University, Seoul 151-742, Korea \\ ${ }^{3}$ Department of Toxicological Evaluation and Research, National Institute \\ of Food and Drug Safety Evaluation, Korea Food \& Drug \\ Administration, Seoul 122-704, Korea
}

\begin{abstract}
The subfamily Murinae is a very controversial group concerning their phylogenetic relationship. Previous studies could not resolve phylogeny among four genera Apodemus, Micromys, Mus and Rattus of the Muridae. In the present study, eight rodent species resident in South Korea were collected and phylogenetically analyzed based on sequence data of five mitochondrial and nuclear DNA regions: 12S rRNA, cytochrome $b$ gene (cyt $b$ ), cytochrome oxidase II (COII), control region of mitochondrial DNA, and a thyroglobulin (Tg) of nuclear DNA. According to the phylogeny of the concatenated data, M. musculus separated early in Murinae (ML 100\%; BA $1.00 \mathrm{pp}$ ) and the genus Rattus grouped with the harvest mouse, M. minutes; these were separated from the genus Apodemus with relatively strong support (ML 74\%; BA $0.76 \mathrm{pp}$ ). The Siberian chipmunk population was also examined using the five genes to obtain better resolution. The phylogeny for Korean rodents determined using the $12 \mathrm{~S}$ rRNA, cyt $b$, COII and control regions discriminated the Siberian chipmunk populations from Korea, Russia, and China.
\end{abstract}

Keywords: phylogeny, nuclear and mitochondrial DNA sequences, Korean rodents

\section{INTRODUCTION}

The order Rodentia is the most specious order of eutherian mammals, representing almost $40 \%$ of the total number of mammalian species (Huchon et al., 2002) and having a worldwide distribution. There are 2,052 rodent species worldwide (Nowak, 1999) and 20 species in five rodent families have been identified in Korea (Yoon et al., 2004). Rodents are very important as laboratory model vertebrates and also as vectors for human diseases (Mills and Childs, 1998).

The molecular phylogeny of rodents has been widelystudied. Despite this knowledge, the subfamily Murinae still remains very controversial, with the phylogeny among the four genera Apodemus, Micromys, Mus, and Rattus of subfamily Murinae remaining unresolved (Michaux et al., 2002). Inconsistent relationships have been inferred based on genetic (Suzuki et al., 2000; DeBry and Sagell, 2001; Michaux et al.,

${ }^{\dagger}$ First two authors contributed equally

*To whom correspondence should be addressed

Tel: $82-2-2287-5288$ or 82-2-880-1274, Fax: $82-2-2287-0070$ or

82-2-888-2754 E-mail: evodevo@smu.ac.kr or hanglee@snu.ac.kr
2007; Lecompte et al., 2008) and other methods (Martin et al., 2000).

Population genetics studies have been accomplished in many rodent species including the Siberian chipmunk. Use of the cytochrome $b$ gene has determined that this species is widely distributed in Korea and neighboring countries such as Russia, China, Japan, and Mongolia (Lee et al., 2008; Koh et al., 2009). These studies also revealed high genetic variation and several phylogroups that nearly mirror the geographic information, although the conclusions were based on use of only the mitochondrial cyt $b$ gene.

The application of mitochondrial and/or nuclear markers can produce better resolution, but this work has rarely taken place (Springer et al., 2001). In addition, the use of multiple gene analysis to study phylogenetic relationships for species and populations becomes increasingly popular (Michaux et al., 2005).

The objective of this study was to clarify the relationship of the subfamily Murinae based on combined data and to investigate the rodent population distribution in Korea, Russia, and China on the basis of the sequences of four mitochondrial genes and a nuclear DNA gene/genomic regions. 
Gila Jung, Seo-Jin Lee, Chuel-kyu Kim, Hang Lee and Chang-Bae Kim

Table 1. PCR primers for five genes/genomes used in this study

\begin{tabular}{|c|c|c|c|}
\hline Gene & Name & Nucleotide sequence $5^{\prime}-3^{\prime}$ & Original publication \\
\hline \multirow{2}{*}{ Cyt $b$} & L14724 & 5'-CGA AGC TTG ATA TGA AAA ACC ATC GTT G-3' & \multirow{2}{*}{ Irwin et al., 1991} \\
\hline & H15915 & 5'-AAC TGC AGT CAT CTC CGG TIT ACA AGA C-3' & \\
\hline \multirow{4}{*}{ 12S rRNA } & $12 \mathrm{C}$ & 5'-AAA GCA AAG CAC TGA AAA TG-3' & \multirow{2}{*}{ Springer et al., 1995} \\
\hline & $12 \mathrm{G}$ & 5'-TTT СAT CTT TTC CTT GCG GTA C-3' & \\
\hline & $\mathrm{F} 2$ & 5'-AAA GCA AGG CAC TGA AAA TG-3' & \multirow{2}{*}{ This study } \\
\hline & R2 & 5'-CCC TTA CGG TAC TTT TTC TAT AGC-3' & \\
\hline \multirow{5}{*}{ Control region } & $\mathrm{F} 1$ & 5'-TTA CYYTGG TCT TGT AAA CC-3' & \multirow{5}{*}{ This study } \\
\hline & R1 & 5'-CAT TTT CAG TGC TाT GCT TT-3' & \\
\hline & F2 & 5'-TTA CCC TGG TCT TGT AAA CC-3' & \\
\hline & R2 & 5'-CAT TTT CAG TGC CTT GCT TT-3' & \\
\hline & F3 & 5'-ATA CAC TGG TCT TGT AAA CC-3' & \\
\hline \multirow{2}{*}{ COII } & F1 & 5'-TTG TCA ARG TTA ART TAT AG-3' & \multirow{2}{*}{ This study } \\
\hline & $\mathrm{R} 1$ & 5'-GGG GTA ATG AAW GAG GCR AA-3' & \\
\hline \multirow{6}{*}{$\operatorname{Tg}$ exong } & $\mathrm{F} 1$ & 5'-TCT ACT TTG AAA CCC CAG-3' & \multirow{6}{*}{ This study } \\
\hline & $\mathrm{R} 1$ & 5'-TCT GAG TTG AAG CAC TGG AC-3' & \\
\hline & $\mathrm{F} 2$ & 5'-CAA GGA ACT CTT TGT TGA CTC TGG-3' & \\
\hline & $\mathrm{R} 2$ & 5'-ACA CAC CAG CAT TCT CCA GCA TAG-3' & \\
\hline & F3 & 5'-TGC CCA CCC AGR ATC AAG GA-3' & \\
\hline & R3 & 5'-AGC ATT CTC CAG CAT AGC ACT G-3 & \\
\hline
\end{tabular}

\section{MATERIALS AND METHODS}

\section{Sampling and DNA extraction}

The tissue samples from eight rodent species: black rat (Rattus rattus), common rat ( $R$. norvegicus), Eurasian red squirrel (Sciurus vulgaris), harvest mouse (Micromys minutus), house mouse (Mus musculus), Korean field mouse (Apodemus peninsulae), Siberian chipmunk (Tamias sibiricus), and striped field mouse (A. agrarius) were obtained from the Conservation Genome Resource Bank for Korean Wildlife. These eight species were collected from major habitats in South Korea (Supplementary data 1). Total DNA was extracted from a small piece of muscle tissue from each species using a DNeasy ${ }^{\circledR}$ Blood \& Tissue Kit (Qiagen, Inc., Valencia, CA).

\section{Polymerase chain reaction amplification and sequencing}

Four mitochondrial gene/genomic regions (cyt $b, 12 \mathrm{~S}$ rRNA, $\mathrm{COII}$ and control region) and one nuclear gene, thyroglobulin (Tg) exon 9, were examined. All primer sets were designed in this study except for the primer sets, L14724 and H15915 for cyt $b$ (Irwin et al., 1991), and 12C and 12G for 12S rRNA (Springer et al., 1995). The detailed information of all primers used for PCR amplification was given in Table 1. The amplified PCR products were sequenced directly on an ABI 3730 automated sequencer (Applied Biosystems, Foster City, CA).

\section{Sequence alignment and phylogenetic analyses}

Sequences were aligned using Clustal W (Thompson et al., 1994) and were edited by eye using Geneious Pro 4.7.6 software (Drummond et al., 2009). The aligned sequences were used to construct the following five data sets: 1) nearly complete cyt $b$ region $1,098 \mathrm{bp} ; 2$ ) nearly complete $12 \mathrm{~S}$ rRNA+ tRNA-Val+partial 16S rRNA alignment length 1,063 bp; 3) nearly complete COII+tRNA-Lys + partial ATP8 gene 796 bp; 4) partial D-loop region alignment length 948 bp, and 5) partial Tg exon 9 in nuclear DNA $644 \mathrm{bp}$. All five data sets were combined for subfamily Murinae analaysis using six species of Murinae, and two species, S. vulgaris and T. sibiricus, as an outgroup. Moreover, five gene/genome regions were separately used for phylogenetic analysis of Korean rodents.

Phylogenetic trees of concatenated five genes and each of the five gene/genome regions were constructed by the maximum-likelihood (ML) method using PAUP *4.0b10 (Swofford 2001) and Bayesian-derived consensus trees (Bayesian inference of phylogenetic trees) using MrBayes 3 (Huelsenbeck and Ronquist 2003). The appropriate model for each gene (cyt $b$ : GTR+I+G, 12S rRNA: GTR+I+G, COII: GTR $+\mathrm{I}+\mathrm{G}$, control region: GTR $+\mathrm{G}, \mathrm{Tg}: \mathrm{SYM}+\mathrm{I}$ ) were determined using hierarchical likelihood-ratio tests performed by MrModeltest 2.3 (Nylander 2004), as implemented in PAUP* $4.0 \mathrm{~b} 10$. For the concatenated data set, the GTR $+\mathrm{I}+\mathrm{G}$ model was selected. A bootstrap analysis was performed with 100 replications to check the ML tree topology robustness. 


\section{RESULTS}

Both the Bayesian and ML trees of concatenated five genes showed the same topology (Fig. 1). According to the phylogenetic trees, M. musculus separated early from the other genera (Apodemus, Rattus and Micromys) in the Murinae with the high values of bootstrap and posterior probabilities (ML 100\%; BA 1.00 pp). The genus Rattus was grouped with the harvest mouse $M$. minutus with high nodal support (ML 100\%; BA $1.00 \mathrm{pp}$ ), and these were separated from the genus Apodemus with relatively weak node confidence (ML $74 \%$; BA $0.76 \mathrm{pp}$ ). All but one of the nodes was supported with strong bootstrap proportion and posterior probabilities (ML 100\%; BA 1.00 pp).

The phylogenetic tree using each of five gene/genome regions showed the tree similar to that of concatenated dataset. The phylogenetic tree of cyt $b$ gene delivered two distinct clades that corresponded to the families Muridae and Sciuridae (Fig. 2). In the Sciuridae clade, $P$. volans grouped with $S$. vulgaris and these were separated from $T$. sibiricus with high posterior probabilities and a low bootstrap proportion (BA 0.95 pp; ML 55\%). No geographical patterns were found in the species tested here except for T. sibricus. Korean and Russian/Chinese populations of $T$. sibiricus were clearly separated (Fig. 2). The mitochondrial 12S rRNA and COII also separated Korean and Russian/ Chinese populations of
T. sibiricus. The mitochondrial control region further provided a separation of the central and the southern part of the Korean population of $T$. sibiricus (unpublished data). However, the $\mathrm{Tg}$ region showed minor intraspecific genetic variation. It did not show genetic diversity depending on locations (data not shown).

\section{DISCUSSION}

The present study reports phylogenetic relationships among four Korean Murinae genera: Apodemus, Micromys, Mus and Rattus. Several genes have been used for the phylogeny of the Murinae to date. On the basis of three genes (IRBP, $12 \mathrm{~S}$ rRNA and cyt $b$ ), DeBry and Sagel (2001) and Michaux et al. (2002) showed that the Apodemus is more closely related to the genus Mus, and that the genus Micromys is separate from the other three genera. Lecompte et al. (2008) examined cyt $b$ and IRBP, and Michaux et al. (2007) examined GHR, cyt $b$ and IRBP. The results of their combined data suggested a sister relationship between Mus and Apodemus; Micromys and Rattus. Suzuki et al. (2000) showed that the genus Apodemus is closer to the genus Micromys than to Mus and Rattus using the IRBP gene. This mirrored the results of Lecompte et al. (2008) and Michaux et al. (2007) using the cyt $b$ gene. Steppan et al. (2005) investigated the

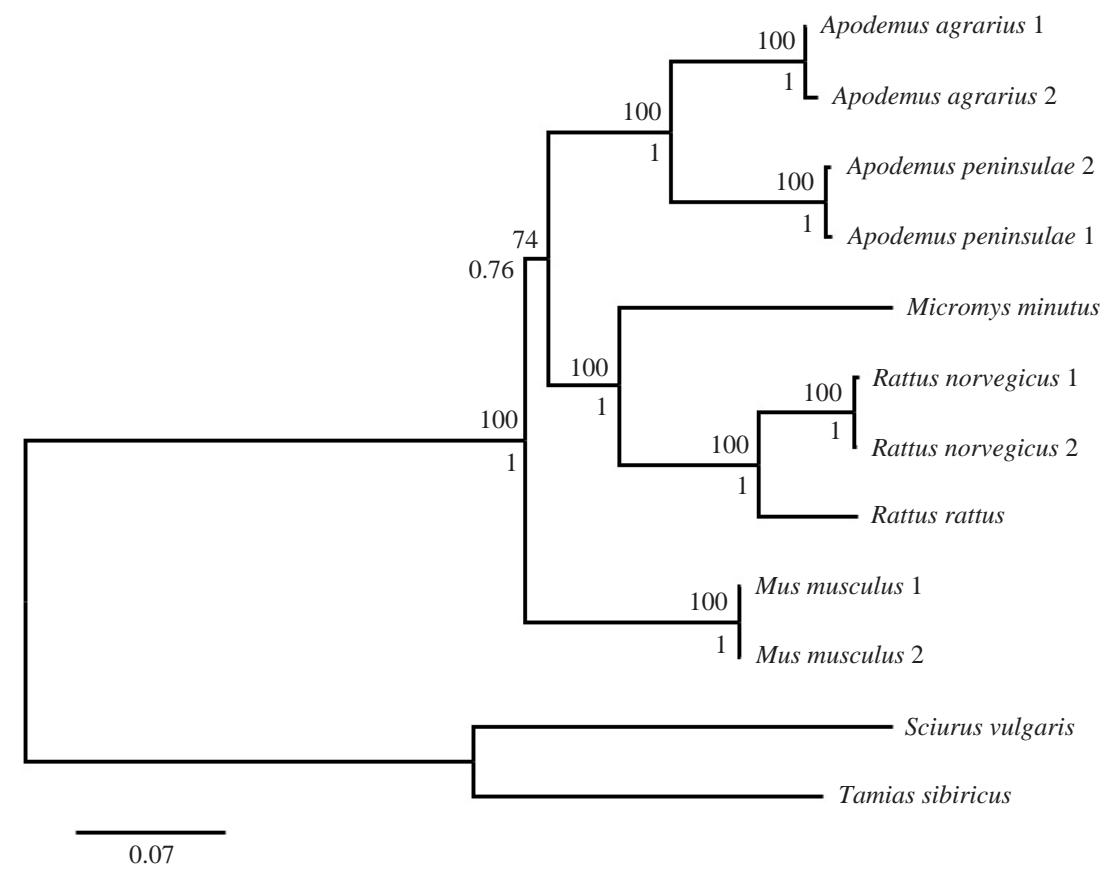

Fig. 1. Maximum likelihood phylogram of eight rodent species based on 4,549 bp concatenated cyt $b, 12 S$ rRNA, COII, control region and $\mathrm{Tg}$. S. vulgaris and T. sibiricus are used to root the tree. Numbers above and below branches are ML bootstrap proportions and Bayesian posterior probabilities, respectively. Nodes with either bootstrap or posterior probabilities $>50 \%$ are indicated. 


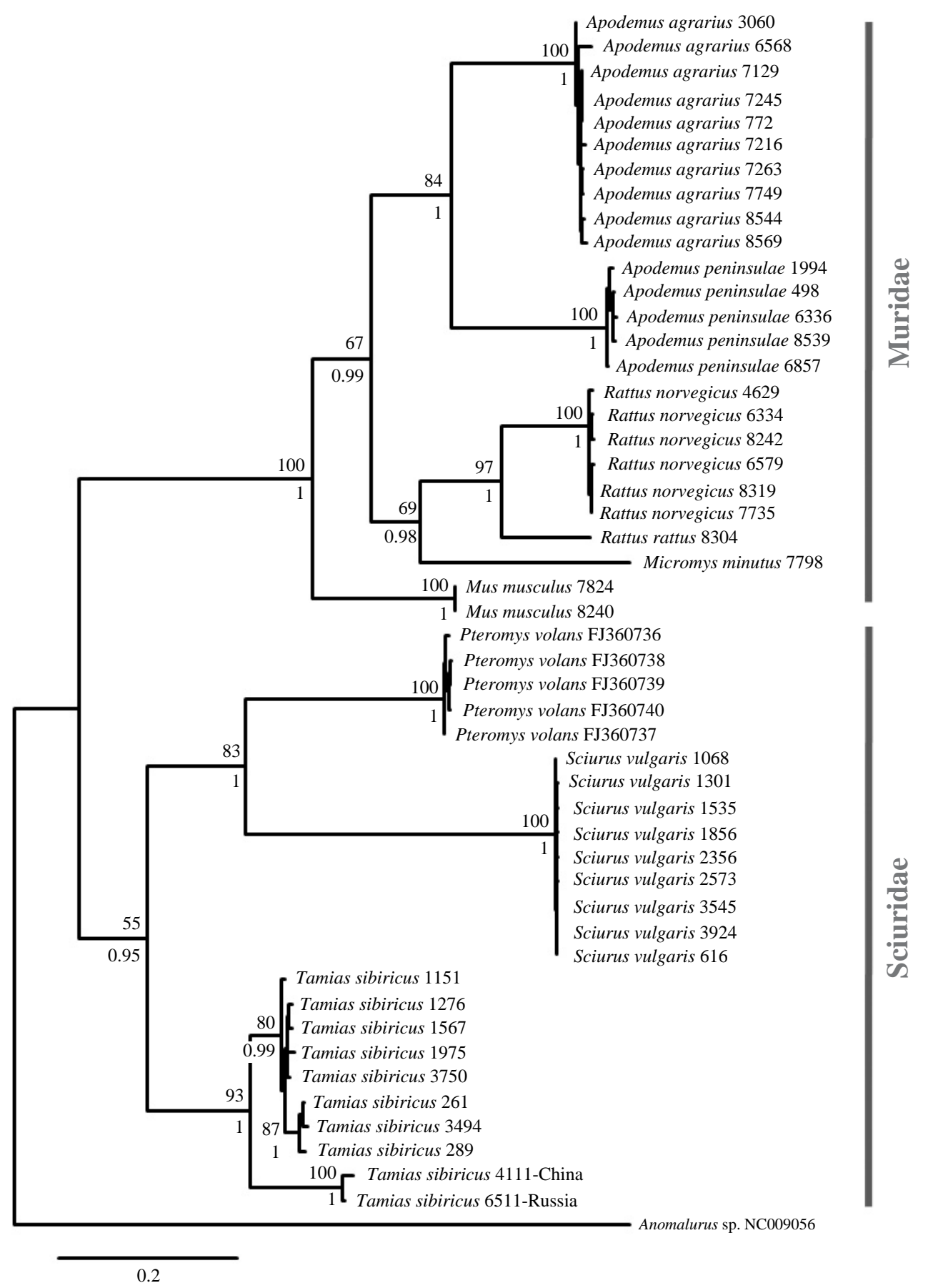

Fig. 2. Maximum likelihood phylogram of nine rodent species based on $1,098 \mathrm{bp}$ of the mitochondrial cytochrome $b$ sequences. The Anomalurus sp. (NC_009056) was used as an outgroup. Numbers above and below branches are ML bootstrap proportions and Bayesian posterior probabilities, respectively. Nodes with either bootstrap or posterior probabilities $>50 \%$ are indicated.

Murinae phylogeny using multiple genes (GHR, RAG1, AP5 and mitochondrial COII+partial COI+ATPase 8), but they did not contain genus Micromys in the analysis.

Contrary to these previous studies, the results of the present study based on five concatenated genes and genome regions suggest that the genus Mus separated early from the other three genera. The genus Micromys was closely related to the genus Rattus and these were separated from the genus Apode- 
$m u s$ with strong support. Our results provided stronger support for the four controversial genera in the subfamily Murinae.

Phylogeny determination using the cyt $b$ gene presently provided a distinction of populations of the Siberian chipmunk from Korea and Russian/Chinese (Lee et al., 2008). Very recently Koh et al. (2009) revealed using the cyt $b$ gene sequences that the Siberian chipmunk from Korea is highly different from the Russian and Chinese populations. Our results from three mitochondrial fragments (cyt $b, 12 \mathrm{~S}$ rRNA and COII), strengthens their findings (unpublished data). Moreover, the analysis of mitochondrial control region separated the central population from the southern population of Korea (unpublished data).

In the present study, a nuclear gene of thyroglobulin ( $\mathrm{Tg}$ ) exon 9, was applied in a novel fashion for the phylogenetic study of the Rodentia. The Tg involved in the thyroid hormone pathway has been scantly studied concerning its evolution and variability among higher taxa. Among mammals, it has been applied only for phylogeny reconstruction among the bear family Ursidae (Pages et al., 2008). Tg showed only a few variations within rodent species, but larger differences among species of the Rodentia. This suggests that the Tg gene is a potential marker for higher phylogeny in the Rodentia. Even though the combined use of the five genes permitted discrete resolution of the genera, further analysis based on more comprehensive species sampling and sequence information would provide a more robust validation of phylogenetic relationships within and among the rodent species.

\section{ACKNOWLEDGEMENTS}

This study was supported by a grant (550-20080074) from KFDA (Korea Food \& Drug Administration)

\section{REFERENCES}

DeBry, R.W. and R.M. Sagel, 2001. Phylogeny of Rodentia (Mammalia) inferred from the nuclear-encoded gene IRBP. Mol. Phylogenet. Evol., 19: 290-301.

Drummond, A.J., B. Ashton, M. Cheung, J. Heled, M. Kearse, R. Moir, S. Stones-Havas, T. Thierer and A. Wilson, 2009. Geneious v4.7, available from http://www.geneious.com.

Huchon, D., O. Madsen, M. Sibbald, K. Ament, M.J. Stanhope, F. Catzeflis, W.W. de Jong and E.J.P. Douzery, 2002. Rodent phylogeny and a timescale for the evolution of glires: evidence from an extensive taxon sampling using three nuclear genes. Mol. Biol. Evol., 19: 1053-1065.

Huelsenbeck, J.P. and F. Ronquist, 2003. MrBayes: a program for the Bayesian inference of phylogeny, 3.0. Rochester, NY.

Irwin, D.M., T.D. Kocher and A.C. Wilson, 1991. Evolution of the cytochrome $b$ gene of mammals. J. Mol. Evol., 32: 128-
144.

Koh, H.S., J. Wang, B.K. Lee, B.G. Yang, S.W. Heo, K.H. Jang and T.Y. Chun, 2009. A phylogroup of the Siberian chipmunk from Korea (Tamias sibiricus barberi) revealed from the mitochondrial DNA cytochrome $b$ gene. Biochem Genet, 47: 1-7.

Lecompte, E., K. Aplin, C. Denys, F. Catzeflis, M. Chades and P. Chevret, 2008. Phylogeny and biogeography of African Murinae based on mitochondrial and nuclear gene sequences, with a new tribal classification of the subfamily. BMC Evol. Biol., 8: 199.

Lee, M.Y., A.A. Lissovsky, S.K. Park, E.V. Obolenskaya, N.E. Dokuchaev, Y.P. Zhang, L. Yu, Y.J. Kim, V. Inaa, A. Myslenkov, T.Y. Choi, M.S. Min and H. Lee, 2008. Mitochondrial cytochrome $b$ sequence variations and population structure of Siberian chipmunk (Tamias sibiricus) in Northeastern Asia and population substructure in South Korea. Mol. Cells, 26: 566-575.

Martin, Y., G. Gerlach, C. Schlotterer and A. Meyer, 2000. Molecular phylogeny of European muroid rodents based on complete cytochrome $b$ sequences. Mol. Phylogenet. Evol., 6: 37-47.

Michaux, J., E. Bellinvia and P. Lymberakis, 2005. Taxonomy, evolutionary history and biogeography of the broad-toothed field mouse (Apodemus mystacinus) in the eastern Mediterranean area based on mitochondrial and nuclear genes. Biol. J. Linn. Soc. Lond., 85: 53-63.

Michaux, J., P. Chevret, M.G. Filippucci and M. Macholán, 2002. Phylogeny of the genus Apodemus with a special emphasis on the subgenus Sylvaemus using the nuclear IRBP gene and two mitochondrial markers: cytochrome $b$ and 12S rRNA. Mol. Phylogenet. Evol., 23: 123-136.

Michaux, J., P. Chevret and S. Renaud, 2007. Morphological diversity of Old World rats and mice (Rodentia, Muridae) mandible in relation with phylogeny and adaptation. J. Zoolog. Syst. Evol. Res., 45(3): 263-279.

Mills, J.N. and J.E. Childs, 1998. Ecologic studies of rodent reservoirs: their relevance for human health. Emerging Infect. Dis., 4: 529-537.

Nowak, R.M., 1999. Walker's Mammals of the World (6th ed). The Johns Hopkins University Press, Baltumore, pp. 12431714.

Nylander, J.A.A., 2004. MrModeltest v2. Program distributed by the author. Evolutionary Biology Centre, Uppsala University.

Pages, M., S. Calvignac, C. Klein, M. Paris, S. Hughes and C. Hänni, 2008. Combined analysis of fourteen nuclear genes refines the Ursidae phylogeny. Mol. Phylogenet. Evol., 47(1): 73-83.

Springer, M.S., R.W. DeBry, C. Douady, H.M. Amrine, O. Madsen, W.W. de Jong and M.J. Stanhope, 2001. Mitochondrial versus nuclear gene sequences in deeplevel mammalian phylogeny reconstruction. Mol. Biol. Evol., 18: 132-143.

Springer, M.S., L.J. Hollar and A. Burk, 1995. Compensatory substitutions and the evolution of the mitochondrial 12S rRNA gene in mammals. Mol. Biol. Evol., 12: 1138-1150. 
Steppan, S.J., R.M. Adkins, P.Q. Spinks and C. Hale, 2005. Multigene phylogeny of the old world mice, Murinae, reveals distinct geographic lineages and the declining utility of mitochondrial genes compared to nuclear genes. Mol. Phylogenet. Evol., 37: 370-388.

Suzuki, H., K. Tsuchiya and N. Takezaki, 2000. A molecular phylogenetic framework for the Ryukyu endemic rodents Tokudaia osimensis and Diplothrix legata. Mol. Phylogenet. Evol., 15: 15-24.

Swofford, D.L., 2001. PAUP*. Phylogenetic analysis using parsimony (*and other methods). Version 4.0b8 (Sunderland,
Massachusetts, Sinauer Associates).

Thompson, J., D. Higgins and T. Gibson, 1994. CLUSTAL W: improving the sensitivity of progressive multiple sequence alignment through sequence weighting, position-specific gap penalties and weight matrix choice. Nucleic. Acids. Res., 22: 4673-4680.

Yoon, M.H., S.H. Han, H.S. Oh and J.K. Kim, 2004. The Mammals of Korea. Dongbang Media, Seoul, pp. 106-144.

Received May 27, 2010 Accepted July 8, 2010 